\title{
Hope for recovery from the pandemic is appearing
}

As I write this Editorial, I am encouraged by the many signs of hope being seen and heard daily - more vaccinations are being made available, the number of "jabs" is generally increasing, and in many regions, the infection rate is down. Unfortunately, there are some signs in the opposite direction that are worrisome. Yet, overall, the changes give hope that a return to more normal life, work, and social patterns is in our future.

The combined science, engineering, medical, and political efforts around the world have enabled the creation and mass production of COVID-19 vaccines. The extensive rate of vaccinations is truly astounding! As the Powder Diffraction Journal (PDJ) community well knows, crystallography contributed on the science side in a significant way. Equally impactful has been the widespread efforts around the globe to adopt new collaborative software tools so that most all could do their best in workflow, collaboration, and communications while trying to maintain safety. We all have adapted to the changes, and to do so required making many changes related to family, community, employment, collaborations, and travel in the last 12 months. Overall, the journal Powder Diffraction has fared well and was published on its regular quarterly schedule. I want to thank all the authors that have submitted manuscripts during this period and responded to the reviewers' and editors' comments throughout the last year. Hopefully most all PDJ readers, like I, have also benefited from multiple virtual learning opportunities and conferences that help keep our knowledge base up to date. I personally appreciate all the efforts that went into these events. As Editor-in-Chief for Powder Diffraction, I also want to publicly thank the entire PDJ Team for their extensive and dedicated during the COVID-19 restrictions, work revisions, and impact on many individuals.

First, the PDJ Editors have been continued to select excellent reviewers. Second, thanks go to these volunteer reviewers who provided the many valuable reviews in a timely manner. These reviews guided the editorial decisions related to each submitted paper. Please take a moment and look at the many names of all the volunteer Editors for PDJ (that information follows directly after the Table of Contents for the Issue). Equally, the ICDD and Cambridge University Press staff who assist in entering the papers into the CUP review system and moving approved papers on through proof manuscript preparation and final review have also worked hard this last year to keep PDJ on schedule. I particularly would like to thank the PDJ Managing Editor Nicole Ernst Boris for the steady and insightful help she has provided during this challenging time.

Thanks once more to all who were associated with PDJ this last year. Your work during these challenging times was much appreciated. As I began, there is hopeful signs that the pandemic situation will continue to improve and in the coming months, we will continue to witness additional improvements. Once it does, I expect to see that PDJ will be strengthened and of more value to the readers of this journal.

Camden Hubbard Editor-in-Chief, Powder Diffraction camden.hubbard@me.com 